\title{
A Survey on Demand Side Management Potential in South- East Europe to Support Transmission Network Flexibility
}

DOI:

10.1109/ISGTEurope.2018.8571693

\section{Document Version}

Accepted author manuscript

Link to publication record in Manchester Research Explorer

\section{Citation for published version (APA):}

Hasan, K., Wang, M., \& Milanovic, J. V. (2018). A Survey on Demand Side Management Potential in South-East Europe to Support Transmission Network Flexibility. In 2018 IEEE PES Innovative Smart Grid Technologies Conference Europe (ISGT-Europe) https://doi.org/10.1109/ISGTEurope.2018.8571693

\section{Published in:}

2018 IEEE PES Innovative Smart Grid Technologies Conference Europe (ISGT-Europe)

\section{Citing this paper}

Please note that where the full-text provided on Manchester Research Explorer is the Author Accepted Manuscript or Proof version this may differ from the final Published version. If citing, it is advised that you check and use the publisher's definitive version.

\section{General rights}

Copyright and moral rights for the publications made accessible in the Research Explorer are retained by the authors and/or other copyright owners and it is a condition of accessing publications that users recognise and abide by the legal requirements associated with these rights.

\section{Takedown policy}

If you believe that this document breaches copyright please refer to the University of Manchester's Takedown Procedures [http://man.ac.uk/04Y6Bo] or contact uml.scholarlycommunications@manchester.ac.uk providing relevant details, so we can investigate your claim.

\section{OPEN ACCESS}




\title{
A Survey on Demand Side Management Potential in South-East Europe to Support Transmission Network Flexibility
}

\author{
Kazi N. Hasan, Mengxuan Wang, and Jovica V. Milanović \\ School of Electrical and Electronic Engineering \\ The University of Manchester \\ Manchester, United Kingdom \\ kazi.hasan@manchester.ac.uk, mengxuan.wang@postgrad.manchester.ac.uk, milanovic@manchester.ac.uk
}

\begin{abstract}
Demand Side Management (DSM) has attracted a huge interest recently in increasing the operational flexibility of modern power systems. This interest is fueled by the integration of a high amount of intermittent renewable energy resources (RES) in the networks. This study has been performed to analyze and identify the potential of DSM in providing the operational flexibility of power networks in 8 South-East European countries. For that purpose, a survey questionnaire was developed on DSM, which was distributed in late 2017 and responses were collected in January 2018. The questionnaire collected information on existing DSM capacities, the required DSM amount for flexible operation and the future DSM potential in the region. Additional key information was collected about the DSM provision, such as the characteristics, location and network services obtained from these resources, as well as the influential market participants to provide these DSM services in the network. This study will facilitate the cross-border management of RES by increasing the operational flexibility of the transmission network in South-East Europe.
\end{abstract}

Index Terms-Demand side management, flexibility, questionnaire, renewable energy, survey.

\section{INTRODUCTION}

The integration of a large amount of intermittent renewable energy resources (RES) adversely affects the flexibility of the operation of a power system [1]. Traditional power systems have been operated in such a way that the conventional power plants (such as base load, intermediate and peaking) are scheduled to follow system loading patterns (i.e. daily, weekly and seasonal). In such systems, the control and provision of flexibility is usually delivered by the supply side control.

The integration of a large amount of intermittent RES in the network is prohibitive to providing total control and a provision of flexibility from the supply side due to the weather dependence of RES resources. For this reason, power systems with a high share of RES are looking for options to obtain the control and provision of flexibility from the demand side [2].

In this aspect, demand side management (DSM) has attracted a huge interest recently in increasing the operational flexibility of modern power systems. DSM is the "actions by consumers to change the amount of electricity they take off the grid at particular times in response to a signal" [3]. DSM offers potential benefits to the entire electricity system, including generation, transmission, distribution and consumers [4]. Several previous studies reported the impact of DSM on transmission and distribution networks [5-8]. The impact of DSM on distribution system operation has been studied in [5] by applying load shifting of a large commercial customer. Another study reported the DSM application by managing domestic heat pumps and thermal energy storage systems [6]. Regarding the transmission level, investment deferral and savings in the high voltage network have been discussed in [7]. The application of DSM in transmission network to alleviate unacceptable voltage conditions and improve network performance under contingencies has been discussed in [8].

Furthermore, several previous studies reported the improvement of network performance, particularly system stability and reliability, by using DSM [9-14]. The improvement of power system short-term voltage stability (i.e. faster voltage recovery) by obtaining DSM from dynamic (motor) loads has been discussed in [9]. Also, the enhancement of voltage stability margin by controlling fastacting flexible loads has been discussed in [10]. On the other hand, the improvement of system frequency stability by using distributed control of household fridge/freezers has been discussed in [11]. The application of decentralized active demand response at distribution level has been discussed in [12] to improve the system frequency profile. Besides, the control of dynamic of to make a delay in frequency-drop has been presented in [13]. Additionally, the improvement of composite (generation and transmission system) reliability by using DSM has been discussed in [14].

Some previous studies highlighted the potential of DSM in some specific countries [15-18]. For example, the whole DSM potential for Swedish industries has been estimated to be in the range of $0.5-2 \mathrm{GW}$, which is 3 to $12 \%$ of the total generation capacity of Sweden [15]. In case of UK, is has been estimated that the industrial and commercial customers can provide 4 to $30 \%$ of their peak load as DSM services [16]. Likewise, the DSM potential from industrial loads across the regions of the Western Interconnect (USA) by 2020 has been estimated to be 1272 to $2540 \mathrm{MW}$, which is 10.1 to $10.4 \%$ of the total load of the regions of the Western Interconnect [17]. 


\section{ACCEPTED VERSION OF THE PAPER}

In the Irish smart metering trial, it has been estimated that as much as $13.9 \%$ of peak residential load can be reduced in Ireland [18].

The current study has been undertaken to estimate the provision of the potential flexibility which can be obtained from DSM to facilitate a secure, reliable and economic operation of the South-East European interconnected transmission network. This survey is conducted as a part of the EU H2020 project CROSSBOW (CROSS-BOrder management of variable renewable energies and storage units enabling a transnational Wholesale market) [19].

The CROSSBOW project is a platform for enabling the aggregated use of RES, DSM and electrical energy storage in 8 South-East European countries. The project is expected to develop a framework and algorithms that will provide a clear guidance and methodology to deploy advanced DSM in order to facilitate an increased cross border power transfer at the national and transnational level, while ensuring at all times network voltage, angular and frequency stability. Moreover, it is expected to enhance the security and economy of the transnational wholesale and ancillary markets. Thus the DSM is expected to participate in the primary, secondary, and tertiary frequency control and intraday energy markets. Furthermore, it will contribute to transmission deferral and distribution deferral services. To address these issues, CROSSBOW will investigate the effect of DSM on overall network steady state and dynamic operation and cross border power exchange.

One of the initial tasks of the CROSSBOW project was to investigate and identify the potential of DSM capacities in the region. The questionnaire was developed to collect information on the DSM about the existing capacities, and the required amount of DSM for the flexible operation and potential future availability of these resources. Additional key information was collected about these resources, such as the characteristics, location, and network services obtained, as well as the influential market participants, to provide these resources in the network. A questionnaire was developed on DSM and distributed in late 2017. The responses were collected in January 2018 from 9 operators of 8 South-East European countries. This paper summarizes some of the key findings of these surveys.

\section{OVERVIEW OF PAST DSM SURVEYS}

A survey is usually conducted for a particular purpose and issued to a selected type of participant. The previous surveys have been conducted on DSM for different purposes.

\section{A. Previous Surveys on Demand Side Management (DSM)}

A theoretical overview of the DSM approaches, implementation and optimization techniques considering the residential customers are presented in [20]. This paper highlighted the issues of uncontrollability and inelasticity of demand in the residential sector. A DSM survey was performed to identify the possibility of shifting peak-load to off-peak periods at the residential customer level in Turkey [21]. This study suggested four generalized residential load profile for summer/winter, weekdays/weekends to design the home energy management system. The demand profiles of the controllable loads in selected residential households in the UK were identified in a survey [22]. The study found that the "time of use" of the peak load can be shifted to the valleys of the daily loading curves. The abovementioned studies considered the DSM procurement at residential customer levels only.

On the other hand, Ofgem (office of gas and electricity markets) conducted a DSM survey on the potential in, and interest of, GB industrial and commercial customers to participate in the DSM scheme [23]. The survey concentrates more on the regulatory and economic aspects than the consideration of the technical performance of the network, and is limited to GB customers only.

Nevertheless, there is no survey, to the best of our knowledge, on the DSM potential at the transmission network level of the South-East European countries, which will be needed to assess the flexibility of the operation of the regional transnational wholesale electricity market. Hence, this survey is undertaken to estimate the provision of potential flexibility, through the DSM resources, to facilitate the secure and economic operation of the South-East European interconnected transmission network.

\section{DEMAND SIDE MANAGEMENT (DSM) SURVEY}

This section discusses the organization of the DSM questionnaire and survey participants.

\section{A. Organization of the Questionnaire}

The questionnaire was developed to identify the potential of DSM in the region. In total 10 questions were asked, as presented in Table I. The questions can be divided into the following five categories: 1) what is the existing DSM capacity, 2) how much DSM capacity is needed, 3) what is the amount of potential DSM, 4) who are the potential providers of DSM, and 5) what are the market mechanisms to obtain the DSM services.

\section{B. Survey Participants}

This survey was conducted as part of the CROSSBOW project and hence all utility partners of the CROSSBOW

TABLE I. DSM SURVEY QUESTIONS

\begin{tabular}{|c|l|}
\hline $\begin{array}{c}\text { Question } \\
\text { No. }\end{array}$ & \multicolumn{1}{|c|}{ Question } \\
\hline Q1 & Representing a transmission or distribution network operator \\
\hline Q2 & Maximum and the minimum yearly demand in the network \\
\hline Q3 & DSM capacity for flexible operation of the network \\
\hline Q4 & $\begin{array}{l}\text { Number of customers could potentially provide DSM and } \\
\text { their DSM capacity }\end{array}$ \\
\hline Q5 & $\begin{array}{l}\text { Top 5 customer categories in the network that have the } \\
\text { largest DSM capacity }\end{array}$ \\
\hline Q6 & $\begin{array}{l}\text { Number of customers that have already signed DSM } \\
\text { contract and their DSM capacity }\end{array}$ \\
\hline Q7 & $\begin{array}{l}\text { Approaches used to receive DSM support from customers } \\
\text { and the corresponding DSM support received }\end{array}$ \\
\hline Q8 & $\begin{array}{l}\text { Number of customers provided DSM over the last 12 } \\
\text { months and their DSM provision }\end{array}$ \\
\hline Q9 & $\begin{array}{l}\text { Top 5 customer categories in the network that provided the } \\
\text { largest DSM support over the last 12 months }\end{array}$ \\
\hline Q10 & Network services and capacity obtained from the DSM \\
\hline
\end{tabular}




\section{ACCEPTED VERSION OF THE PAPER}

consortium contributed to the survey. The questionnaire was distributed over November-December 2017 and the responses were collected in January 2018. All 9 TSOs and DSOs responded to the survey.

\section{RESULTS OF THE DSM SURVEY}

This section presents the results of the DSM survey and analyzes the response of each question separately.

\section{A. Q1: Representing a transmission or distribution network}

This question identified the respondent and their working horizon. In total 8 respondents were from the TSO and 1 from the DSO.

\section{B. Q2: Maximum and the minimum yearly demand in the network}

The response to this question is shown in Fig. 1. The amount of maximum demand gives an indication of the size of the network. The maximum demand varies from $653 \mathrm{MW}$ to 9,771 MW and minimum demand varies from $174 \mathrm{MW}$ to 4,085 MW. Four countries among eight have maximum demand more than $6000 \mathrm{MW}$, two have less than $2000 \mathrm{MW}$, and the other two have in between 2000 and $6000 \mathrm{MW}$. Maximum demand occurs in all countries during the winter season (December - February) and minimum demand occurs in the summer season (May - July). Fig. 1 shows the variations in the amount of consumption in the region between maximum and minimum demand.

\section{Q3: Required DSM capacity (MW) for flexible operation of the network}

This question captured the TSO and DSO's views on the requirement of the amount of DSM in their network. The responses are presented in Fig. 2. The amount of DSM requirement varies between $80 \mathrm{MW}$ to $4263 \mathrm{MW}$. Six TSOs identified their DSM requirements as 100, 600, 4263, 80, 140, and $100 \mathrm{MW}$, which is $15 \%, 8 \%, 47 \%, 5 \%, 7 \%$ and $1.5 \%$ of their maximum demand (as in Q2), respectively.

The preferable time for DSM procurement in the network is shown in Fig. 3. The preferred periods of day for DSM procurement based on the number of responses are evening $(n=6)$, and afternoon $(n=4)$ followed by late night $(n=3)$, and morning $(n=2)$. It can be seen from Fig. 3 that weekdays $(n=3)$ are more popular for DSM procurement than weekends $(n=1)$, where $\mathrm{n}$ is the number of responses.

\section{Q4: Number of customers that could potentially provide DSM and their DSM capacity $(M W)$}

The numbers of potential customers that could participate in DSM and corresponding DSM capacity in the network is presented in Fig. 4. The number of customers varies from 0 to 15 , and the amount of potential DSM capacity varies from 0 to $200 \mathrm{MW}$. The potential of DSM is very low compared to the maximum demand in the network, i.e., it is $1 \%, 1 \%, 3 \% 3 \%$, $7 \%$, and $8 \%$ of the maximum demand in respective networks (two TSOs did not respond to this question). This is notably lower (on average less than a half of required) than what TSO's would actually like to have.

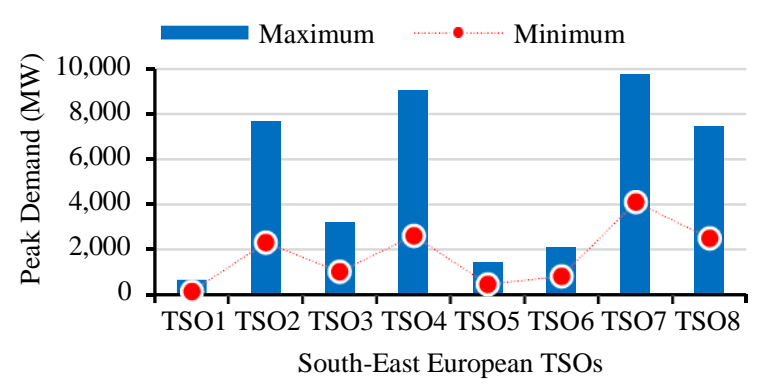

Fig. 1 DSM-Q2: maximum \& minimum demand in different TSOs.

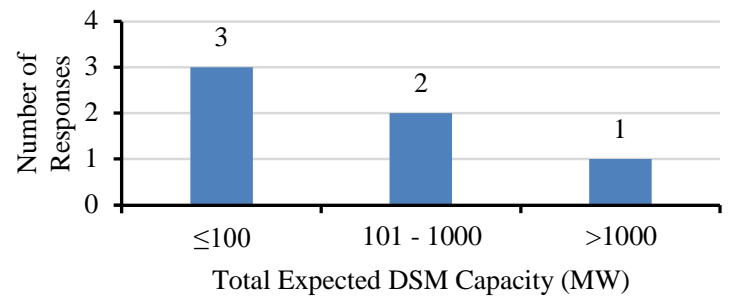

Fig. 2 DSM-Q3: total expected DSM capacity in the region.

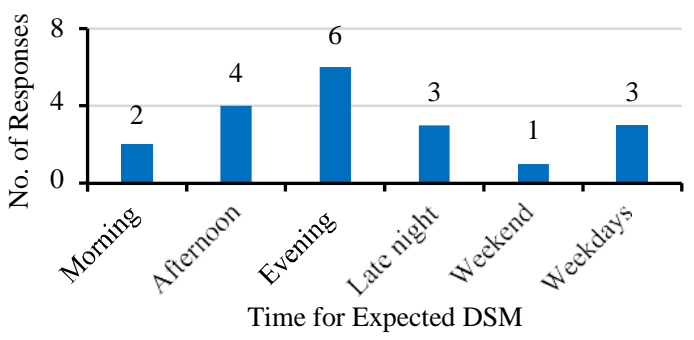

Fig. 3 DSM-Q3: preferred time for DSM acquisition.

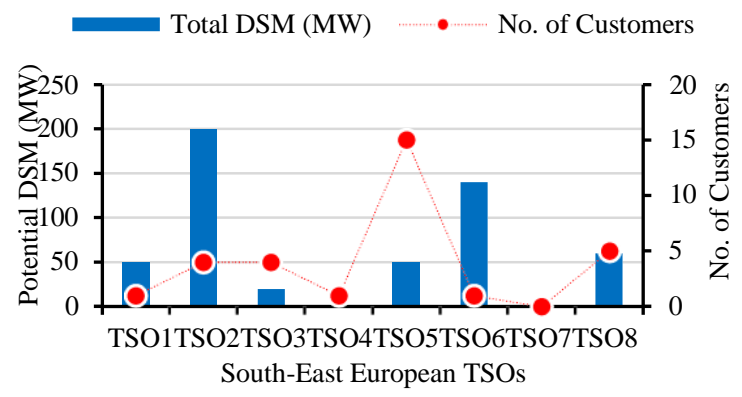

Fig. 4 DSM-Q4: potential DSM capacity.

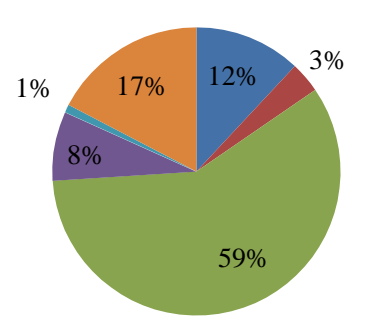

- Mining and Quarrying

- Chemicals and Allied Industry

- Steel and Primary

Metal Industries

-Stone, Clay, Glass and

Concrete Products

- Paper and Allied

Products

- Hydro Pump

Fig. 5 DSM-Q5: largest DSM providers in the region. 


\section{ACCEPTED VERSION OF THE PAPER}

E. Q5: Categories of customers with the largest (based on their size) DSM capacity

The type of customers with the largest DSM capacity and their DSM potential in the network were identified in this question, see Fig. 5. It was found that DSM can be obtained from mining and quarrying $(n=3)$, chemicals and allied industry $(n=3)$, steel and primary metal industry $(n=4)$, stone, clay, glass and concrete products $(n=2)$, paper and allied products $(n=2)$, and hydro pump $(n=2)$, where $n$ is the number of responses.

As can be seen from Fig. 5, the highest amount of DSM can be obtained from steel and primary metal industries (59\%), followed by mining and quarrying $(12 \%)$, and stone, clay, glass and concrete products ( $8 \%$ ). In total 2,190 MW DSM can be obtained from the top 5 customer types.

\section{F. Q6: Number of customers that have already signed DSM contract and their DSM capacity (MW)}

Fig. 6 shows the response to this question, which is the amount of contracted DSM in the network. There are 4 TSOs who do not have any DSM contract yet with their customers.

Four countries out of eight have a DSM contract with 50, 140, 240 and $1255 \mathrm{MW}$ capacities, which are $7 \%, 1 \%, 7 \%$ and $14 \%$ of the maximum demand of those countries, respectively.

As can be seen from Fig. 6, the number of customers varies from 1 to 37 and total contracted DSM capacity varies between $50 \mathrm{MW}$ and $1255 \mathrm{MW}$. The DSM customers are connected to different voltage levels in the transmission networks including $20,35,110,150,220$ and $400 \mathrm{kV}$.

\section{G. Q7: Approaches used to receive DSM support from customers and the received DSM capacity $(M W)$}

The market mechanisms to obtain DSM were identified in this question, as shown in Fig. 7. As can be seen from Fig. 7, the highest amount of DSM is obtained from the hydro power plants $(50 \%)$, followed by pre-agreed DSM contract $(33 \%)$, and manual control by TSO (11\%).

In terms of the DSM techniques and the number of TSOs, the market mechanism includes pre-agreed contract $(n=2)$, automated control by TSO/DSO $(n=1)$, manual control by TSO $(n=1)$, and contract for tertiary control with hydro pump storage $(n=1)$. Currently, four TSOs use these approaches and four TSOs did not take part in the DSM.

\section{H. Q8: Number of customers provided DSM over the last 12 month and their DSM provision (MWh)}

Fig. 8 shows the amount of DSM obtained over the last 12 months in the region. Only three out of nine participants responded to this question. As can be seen from Fig. 8, the amount of DSM obtained by different TSOs is in between 80 and 25,739 MWh. The number of customers varied between 1 and 23 .

The survey also found the number of DSM events is in between 1 and 20, and total duration of the DSM is between 2 to 100 hours. The times for DSM provision were morning, afternoon and late night. It is worth noting that six out of nine TSOs had not received DSM support at all, and further two had very little, over the last 12 months.

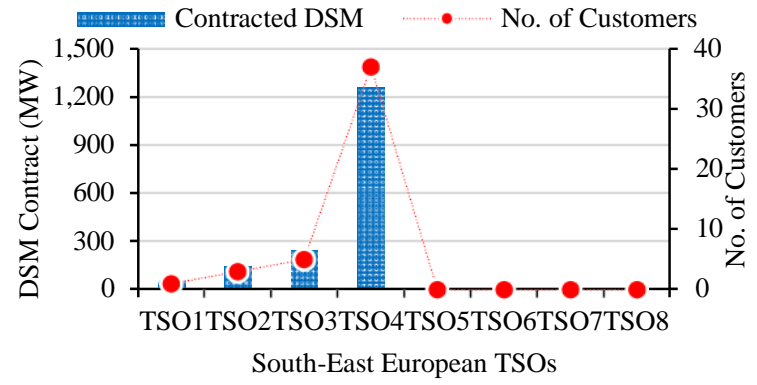

Fig. 6 DSM-Q6: capacity of existing DSM contract in the region.

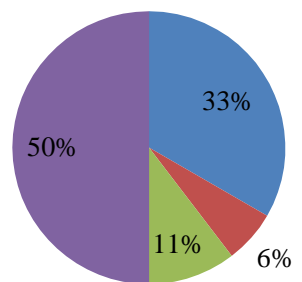

- Pre-agreed DSM

contract

- Automated control by TSO/DSO

Manual control by TSO

Hydro Pump storage

Fig. 7 DSM-Q7: market mechanisms for DSM acquisition.

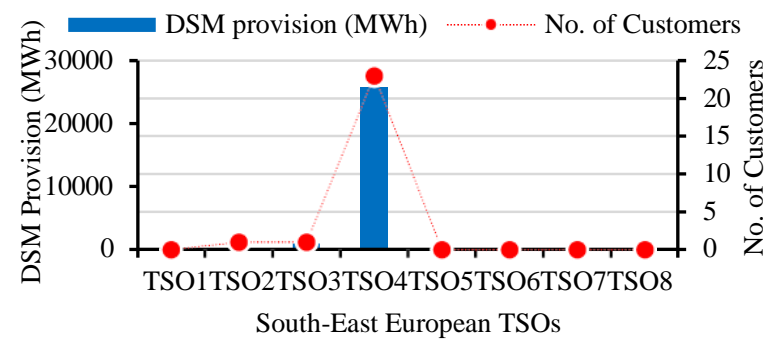

Fig. 8 DSM-Q8: DSM provision over the last 12 months.

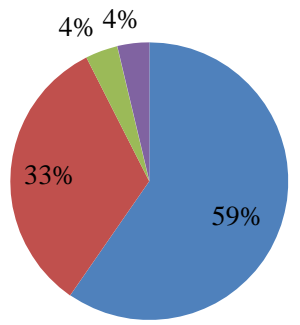

- Steel and Primary

Metal Industries

- Stone, Clay, Glass and

Concrete Products

Hydro Pump storage

- Chemicals and Allied Industry

Fig. 9 DSM-Q9: top DSM providers over the last 12 months.

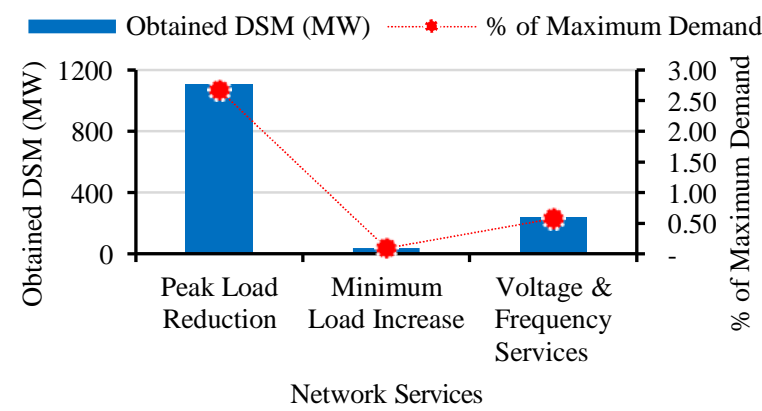

Fig. 10 DSM-Q10: network services obtained from DSM. 


\section{ACCEPTED VERSION OF THE PAPER}

I. Q9: Top 5 customer categories that provided the largest DSM support (based on their size) over the last 12 months

Fig. 9 presents the top customers (i.e. types of loads), who provided the highest amount of DSM services over the last 12 months. The categories of DSM providers are steel and primary metal industries (15,208 MWh), stone, clay, glass and concrete products $(8,395 \mathrm{MWh})$, hydro pump (960 MWh) and chemicals and allied industry $(942 \mathrm{MWh})$, which are $59 \%$, $33 \%, 4 \%$, and $4 \%$, respectively, of the total obtained DSM over the last 12 months.

\section{J. Q10: Network services and capacity obtained from the DSM}

Fig. 10 presents the network services obtained from DSM during the past year. These are peak load reduction (1105 MW), minimum load increase (40 MW), and ancillary (voltage, frequency) services (240 MW), which are $2.67 \%, 0.10 \%$, and $0.58 \%$, respectively, of the maximum regional demand. It suggests that the reduction of peak load is the most popular reason to obtain DSM.

\section{CONCLUSIONS}

This paper presents a summary of the results of a survey on the estimation of the potential for demand side management. The survey was conducted, at this stage, for 8 South-East European countries to facilitate the operational flexibility of power networks by improving the cross-border management of variable renewable energies and storage units enabling a transnational wholesale market.

The survey was conducted to identify the following major aspects of the DSM in the region: 1) what is the existing DSM capacity, 2) how much DSM capacity is needed, 3) what are the potential providers/technologies for DSM, and 4) what network services could be provided by (or expected to obtain from) the DSM services.

The survey indicates that there is a lack of DSM facilities in the region relative to the total electricity generation capacity and consumption, and installed capacity of intermittent renewable energy. The region has a total $64 \mathrm{GW}$ generation capacity, $34 \mathrm{GW}$ peak loads, $12 \mathrm{GW}$ (18\% of the total installed capacity) intermittent renewable (wind and PV) generation capacity. The total intermittent renewable generation capacity in the region is $36 \%$ of the maximum demand. Hence, a high amount of flexibility resources (such as DSM) is required for such a system to facilitate the increased penetration of renewables.

The total DSM capacity in the region is $5 \%$ of the peak load. Four countries out of eight do not have DSM resource at transmission level. Four countries out of eight have a DSM contract with 50,140, 240 and $1255 \mathrm{MW}$ capacities, which are $7 \%, 1 \%, 7 \%$ and $14 \%$ of the peak load of those countries, respectively.

The required DSM capacities in different South-East European countries have been identified. Five participants identified their DSM requirements as 100, 600, 4263, 80 and $140 \mathrm{MW}$, which is $15 \%, 8 \%, 47 \%, 5 \%$ and $7 \%$ of their peak load, respectively. This will increase the DSM to peak load ratio in the region from $5 \%$ to $20 \%$.

The potential DSM providers in the region have been recognized. The prevalent DSM providers are identified as steel and primary metal industry, mining and quarrying, chemicals and allied industry, stone, clay, glass and concrete products, paper and allied products, and pumped hydro generation.

The network services, which the TSOs and DSO would like to obtain from DSM, have been identified. The network services obtained by DSM are peak load reduction, minimum load increase, and ancillary (voltage and frequency) services.

The main purpose of this survey was to identify the available capacity and potential for DSM in the region covered by the CROSSBOW countries. An extension of this survey to other TSOs in Europe and in the world will follow in the near future and it will provide more detailed information about current DSM practices and future plans for greater reliance on it for provision of network services.

This survey was deliberately high level and reasonably simple to ensure high response rate and such facilitate timely assessment of industrial state of the art in this area for project implementation.

The results of this survey are useful to broadly estimate the DSM potential in the South-East European countries in order to provide the flexibility of operation of existing and future power systems. Having this information, the electrical power network of the region can next be studied to facilitate cross-border power transfer and increase renewable energy penetration in the electricity grid, while ensuring the appropriate voltage and frequency profile and maximum benefit to the network.

A more comprehensive questionnaire though, with questions on, e.g., DSM implementation mechanisms, contracts with customers, entities involved in the DSM implementation process, DSM pricing etc. would be needed in order to develop specific framework for efficient DSM implementation. A questionnaire of this type will be developed and distributed in the future.

\section{ACKNOWLEDGMENT AND DISCLAIMER}

The authors would like to acknowledge the support of colleagues from the utilities and system operators, who took part in the survey to respond to the questionnaire and kindly shared their knowledge and experience.

This research is supported by the EU H2020 project CROSSBOW ( Grant Agreement no. 773430).

This paper reflects only the author's views and neither the Agency nor the Commission are responsible for any use that may be made of the information contained therein.

\section{REFERENCES}

[1] California ISO, "Integration of Renewable Resources at $20 \%$ RPS," Aug 2010. [available] http://www.caiso.com/Documents/ Integration-RenewableResources-OperationalRequirementsand GenerationFleetCapabilityAt20PercRPS.pdf

[2] D. Stenclik, P. Denholm, and B. Chalamala, "Maintaining Balance: The Increasing Role of Energy Storage for Renewable Integration," IEEE Power and Energy Magazine, vol. 15, no. 6, pp. 31-39, 2017.

[3] M. Woolf, T. Ustinova, E. Ortega, H. Brien, P. Djapic and G. Strbac, "Distributed generation and demand response services for the smart distribution network," Report A7 for the "Low Carbon London" LCNF project: Imperial College London, 2014. 


\section{ACCEPTED VERSION OF THE PAPER}

[4] UK Office of Gas and Electricity Markets. 2015 Making the electricity system more flexible and delivering the benefits for consumers. Position paper. See https://www.ofgem.gov.uk /ofgem-publications/96959/flexibilitypositionpaperfinal-pdf.

[5] Strbac G. 2008 Demand side management: benefits and challenges. Energy Policy 36, 4419-4426. (doi:10.1016/j.enpol.2008.09.030)

[6] A. Arteconi, N. J. Hewitt and F. Polonara, "Domestic demandside management (DSM): Role of heat pump and thermal energy storage (TES) systems," ELSEVIER, Applied Thermal Engineering 51 (2013) 155-165.

[7] S. W. Hadley and A. H. Sanstad. "Impacts of Demand-Side Resources on Electric Transmission Planning." ORNL., Oak Ridge, Tennessee, USA. January, 2015.

[8] B. P. Hayes, A. J. Collin, J. L. Acosta and S. Z. Djokic, "Assessment of the Influence of Distributed Generation and Demand Side Management on Transmission System Performance," $7^{\text {th }}$ Mediterranean Conference and Exhibition on Power Generation, Transmission, Distribution and Energy Conversion, Agia Napa, Cyprus, November, 2010.

[9] Y. Dong, X. Xie, K. Wang, B. Zhou and Q. Jiang. "An Emergency-Demand-Response Based Under Speed Load Shedding Scheme to Improve Short-Term Voltage Stability," IEEE Trans. Power Systems, vol. 32, pp. 3726-3735. Sept. 2017.

[10] M. Yao, J. L. Mathieu and D. K. Molzahn. "Using Demand Response to Improve Power System Voltage Stability Margins".

[11] H. W. Qazi and D. Flynn. "Analysing the impact of large-scale decentralized demand side response on frequency stability," ELSEVIER. Electrical Power and Energy Systems 80 (2016) 1-9.

[12] G. Benysek, J. Bojarski, M. Jarnut and R. Smolenski. "Decentralized Active Demand Response (DADR) system for improvement of frequency stability in distribution network," ELSEVIER. Electrical Power Systems Research 134 (2016) 8087.

[13] J. A. Short, D. G. Infield and L. L. Freris. "Stabilization of Grid Frequency Through Dynamic Demand Control," IEEE Trans. Power Systems, vol. 22, pp. 1284-1293, July 2007.
[14] M. Zhou, G. Li and P. Zhang, "Impact of Demand Side Management on Composite Generation and Transmission System Reliability." IEEE PES Power Systems Conference and Exposition, pp. 819-824, 2006.

[15] S. Esmailnajad and J. Sundquist, "Demand Side Management in Swedish Industry-An investigation of load management in major Swedish industries". Chalmers University of Technology, Goteborg, Sweden, 2014.

[16] Element Energy. (2012) "Demand side response in the nondomestic sector - Final report for Ofgem."

[17] M. Starke, N. Alkadi and O. Ma. "Assessment of Industrial Load for Demand Response across U.S. Regions of the Western Interconnect," ORNL., Oak Ridge, Tennessee, USA. Sept. 2013.

[18] E. Diskin and T. Fallon, "Implementation of demand side management as a solution for distribution network operation and management," CIRED Wokrshop, Lisbon, May, 2012.

[19] CROSSBOW. [available] http://crossbowproject.eu/

[20] B. P. Esther and K. S. Kumar, "A survey on residential Demand Side Management architecture, approaches, optimization models and methods," Renewable and Sustainable Energy Reviews, vol. 59, pp. 342-351, 2016/06/01/ 2016.

[21] O. Elma and U. S. Selamoğullar, "A survey of a residential load profile for demand side management systems," in 2017 IEEE International Conference on Smart Energy Grid Engineering (SEGE), 2017, pp. 85-89.

[22] J. Palmer, N. Terry, and T. Kane, "Further Analysis of the Household Electricity Survey; Early Findings: Demand side management. https://www.gov.uk/government/uploads/system/ uploads/attachment_data/file/275483/early_findings_revised.pdf , 2013.

[23] OFGEM, "Industrial \& Commercial demand-side response in GB: barriers and potential", Oct. 2016, [available] https://www.ofgem.gov.uk/publications-and-updates/industrialcommercial-demand-side-response-gb-barriers-and-potential 